Revista Aspas

ppgac - USP

Desenhos de Pesquisa

\title{
POÉTICAS NÔMADES: PROCESSOS DE CRIAÇÃO EM AGENCIAMENTOS DO EU NO (COM O) OUTRO
}

NOMADIC POETICS: CREATIVE PROCESSES IN AGENCIES OF ME IN (WITH) THE OTHER

POÉTICAS NÓMADAS: PROCEDIMIENTOS CREATIVOS EN LA MEDIACIÓN DEL YO EN EL (CON EL) OTRO

\section{José Flávio Gonçalves da Fonseca}

José Flávio Gonçalves da Fonseca Doutorando em Artes pela Universidade Federal do Pará. Artista cênico e professor assistente do curso de Teatro da Universidade Federal do Amapá (Unifap). 


\section{Resumo}

Este artigo se propõe a discutir o processo de pesquisa Poéticas nômades realizada a partir da criação artística por meio da relação entre artistas de espaços geográficos diferentes em meio a sua condição de nômade. A pesquisa apontou para a realização de uma obra que ocorra em espaços diversos, simultaneamente, por meio de ambientes virtuais de transmissões on-line. Assim, será discutida a ideia de realização artística em espaços cíbridos (hibridização dos espaços físicos reais e do ciberespaço), bem como a condição ubíqua da arte em meio à tecnologia, capaz de proporcionar aos corpos habitarem espaços diversos em um mesmo tempo presente.

Palavras-chave: Teatro, Processo de criação, Pesquisa Poética, Ubiquidade, Corpo e Virtualidade.

\section{Abstract}

This article proposes to discuss the research process of Poéticas nômades carried out from the artistic creation through the relation between artists of different geographic spaces amid their nomadic condition. The research has pointed to the realization of a work that takes place in different spaces, simultaneously, through virtual environments of online transmissions. Thus, the idea of artistic realization in cybrid spaces (hybridization of real physical spaces and cyberspace) will be discussed, as well as the ubiquitous condition of art in the midst of technology, capable of allowing bodies to inhabit different spaces in the same present time.

Keywords: Theater, Creation process, Poetic Research, Ubiquity, Body and Virtuality.

\section{Resumen}

Este artículo se propone discutir el proceso de investigación Poéticas nômades realizada a partir de la creación artística a través de la relación entre artistas de espacios geográficos diferentes en medio de su condición de nómada. La investigación muestra la realización de una obra que se lleva a cabo en espacios diversos, simultáneamente, a través de ambientes virtuales de transmisiones en línea. Así, se discutirá la idea de realización artística en espacios cíbridos (hibridación de los espacios físicos reales y del ciberespacio), así como la condición ubicua del arte en medio de la tecnología, capaz de proporcionar a los cuerpos estar en espacios diferentes en un mismo tiempo presente.

Palabras clave: Teatro, Proceso de creación, Investigación poética, Ubiquidad, Cuerpo y Virtualidad. 
Este trabalho objetiva traçar uma discussão no campo da pesquisa poética. Nesse sentido, consideram-se aqui as implicações acerca desta opção que se encontra em um território movediço no âmbito do universo acadêmico brasileiro. Segundo o professor dr. Flávio Gonçalves (2009), do curso de Artes Visuais da Universidade Federal do Rio Grande do Sul, em seu artigo intitulado "Um argumento frágil" publicado na Revista Porto Arte do Programa de Pós-graduação em Artes Visuais do Instituto de Artes da UFRGS:

A pesquisa em Poéticas Visuais na Universidade Brasileira possui uma história recente que parece configurar-se na busca de um lugar e de uma forma que the sejam próprias, que Ihe confiram a autoridade que o conhecimento desenvolvido a partir de uma produção em arte possa produzir. (GONÇALVES, 2009, p. 138)

O autor toma como referência especificamente a pesquisa no campo das Poéticas Visuais, considerando, portanto, o universo das Artes Visuais, mas que aqui podemos trazer para uma discussão expandida no campo das Artes na sua diversidade de linguagens e seus hibridismos.

Ainda nessa perspectiva, Flávio Gonçalves (2009) aponta para um paradoxo na relação entre o artista e sua condição de pesquisador dentro do ambiente acadêmico, no sentido de que "as questões de arte e de sua fatura, quando abordadas por estes, tomam uma dimensão diferenciada daquelas conduzidas por teóricos, pois a posição e envolvimento em relação à arte são distintos" (Ibid., p. 138). A relação paradoxal aqui se encontra no confronto de "se a tarefa de produzir arte é própria da definição mesma de artista, a reflexão formal deste processo, representada na academia pelas poéticas visuais, não o é necessariamente" (Ibid., p. 138).

Portanto, a pesquisa em poéticas operaria, nesse sentido, em um ambiente de fronteira entre a prática artística e o pensamento formal. Cabe aos sujeitos que alimentam essas pesquisas - comumente relacionados a partir do binômio artista-pesquisador - produzirem argumentos (que se darão inclusive no âmbito de um discurso por via da prática) que fortaleçam a presença da pesquisa poética no território acadêmico brasileiro, mesmo sob a consciência de que, sob a ótica do pensamento científico, o argumento da pesquisa em arte ainda se apresente como um "argumento frágil" (Ibid.). 
Contudo, a fragilidade aqui apontada se mostra muito mais como um desvio do que uma contrariedade, uma vez assumindo a possibilidade de a pesquisa em arte se estabelecer enquanto campo independente, cuja promoção de uma emancipação epistemológica da arte permita que a prática artística se mostre na sua potência, não sendo subjugada a um pensamento científico formal.

Como exposto acima, este trabalho visa discutir uma investigação poética, o que justifica a argumentação tecida até então. Este estudo apresenta-se como minha investigação de doutorado no programa de pós-graduação em Artes da Universidade Federal do Pará, dentro da linha de pesquisa em Poéticas e Processos.

Denominada Poéticas nômades, a pesquisa visa investigar a realização de um processo de criação a partir da construção coletiva feita entre artistas que se encontram em territórios geográficos distintos. Portanto, busca-se, aqui, trabalhar no âmbito dos agenciamentos poéticos: a criação artística que se possibilita pela interação poética que rompe distâncias por meio dos dispositivos e ambientes digitais, em específico, no ambiente da web, o que vai ao encontro das discussões sobre telepresença, ubiquidade dos corpos na relação entre arte, vida e tecnologia, além dos hibridismos entre o espaço físico e o espaço cibernético.

A pesquisa vai problematizar a noção de nômade, buscando na filosofia de Deleuze e Guattari (1997) a compreensão da relação da condição nômade na esfera da criação artística. Segundo os autores:

O nômade não tem pontos, trajetos, nem terra, embora evidentemente ele os tenha. Se o nômade pode ser chamado de o desterritorializado por excelência, é justamente porque a reterritorialização não se faz depois, como no migrante, nem em outra coisa, como no sedentário (com efeito, a relação do sedentário com a terra está mediatizada por outra coisa, regime de propriedade, aparelho de Estado...). Para o nômade, ao contrário, é a desterritorialização que constitui sua relação com a terra, por isso ele se reterritorializa na própria desterritorialização. É a terra que se desterritorializa ela mesma, de modo que o nômade aí encontra um território. (Ibid., p. 38)

Assim, a condição nômade, em sua compreensão expandida, que rompe a mera intervenção no espaço geográfico, apresenta-se como operativo no processo de criação artística desenvolvida. O nômade, portanto, vai lidar com 
a desterritorialização e com a reterritorialização, em uma simultaneidade operativa. Assim, essa operação de reterritorialização reterritorializante possibilita a construção poética.

É, portanto, com o território, do ponto de vista do nômade em Deleuze e Guattari que esta pesquisa poética trabalha. Territórios virtuais, territórios atuais, territórios sensíveis. E nessa perspectiva ocorrem os agenciamentos e atravessamentos imprescindíveis para tal.

Nessa ideia de agenciamento afetivo, trago como atravessamentos quatro territórios sensíveis, que se mostram contribuindo diretamente no desenvolvimento da investigação poética aqui discutida. Esses territórios sensíveis configuram-se em pessoas e/ou obras que influenciam diretamente minha reflexão e que, nos agenciamentos sensíveis, contribuem para a construção da pesquisa acerca de uma poética nômade.

O primeiro agenciamento se mostra na figura do meu orientador de pesquisa, aquele com o qual confronto os pensamentos que povoaram incialmente minhas inquietações e que, em uma relação de contribuição sensível na pesquisa, apresenta provocações no intuito de produzir conhecimento acerca das questões de início levantadas em um movimento criador.

O segundo agenciamento ocorre a partir da obra de artistas que, em seus territórios de atuação, influenciam diretamente minha investigação. Esses artistas trabalham necessariamente com questões voltadas para a pesquisa poética, tendo como suporte as reflexões sobre corpo, audiovisual e tecnologia. São eles: o grupo de pesquisa Corpos Informáticos, liderado pela professora Beatriz Medeiros, da Universidade de Brasília, e o grupo de pesquisa Poéticas Tecnológicas: Corpo Audiovisual, da Universidade Federal da Bahia.

O terceiro agenciamento se dá pela via das obras escritas, resultantes de pesquisas no campo das poéticas, bem como outras referências que têm como fonte as pesquisas no campo das poéticas tecnológicas. Desse modo, como atravessamentos teóricos de partida, encontram-se Deleuze e Guattari (1997), nos seus escritos sobre o estado de nômade, Haseman (2006) e suas discussões sobre a pesquisa performativa ${ }^{1}$, além de Katz e

1. Ao longo da última década, muitos pesquisadores qualitativos têm chegado à mesma conclusão. Limitados pela capacidade das palavras para captar as nuances e sutilezas 
Greiner (2005), nas discussões sobre a noção de corpomídia². Esses autores se encontram no início da pesquisa que posteriormente ganha outras relações de agenciamento, tais como Pierre Levy (2007) e sua obra O que é virtual?, Adauto Novais (2005), na obra Muito além do espetáculo, além das contribuições sobre o processo de criação na obra de Cecília Almeida Salles (2008) e Sônia Rangel (2006, 2008), esta última com contribuição significativa na construção e no desenrolar da pesquisa até este momento, cuja discussão será realizada mais à frente neste artigo.

Por fim, o quarto agenciamento sensível advém dos artistas colaboradores que, por hora, estou chamando de artistas nômades. Eles - assim como eu - estão na condição de constantes deslocamentos e são os sujeitos responsáveis pela construção, junto comigo, do processo de criação em que a pesquisa ocorre.

São eles quatro artistas individuais e mais um coletivo de artistas. Fabiano Rocha, cearense, natural do município de Russas, morando em Fortaleza, é ator e dançarino. Débora Ingrid, cearense, natural do município de Russas, morando em Fortaleza, recém-chegada de São Paulo, onde morou por um ano e com uma experiência passageira pela Índia, é atriz e diretora. Henrique Oliveira, cearense, natural e morador do município de Quixeré, atuando artisticamente em Fortaleza, é ator e artista audiovisual. Ícaro Lourenço, cearense, natural do município de Russas, morando em Fortaleza, é ator, músico e artista audiovisual. Coletivo TensoAtivo, grupo de artistas atuantes na cidade de Macapá, no estado do Amapá, que tem como linha investigativa a performance arte e a intervenção urbana, liderado pela professora Cristiana Nogueira.

Esses artistas/coletivo nômades interagem diretamente comigo, na figura de artista-pesquisador e proponente desta pesquisa, mas que também se reconhece como um quinto elemento - artista nômade. Assim, eu também me reconheço como um desses elementos: Flávio Gonçalves, cearense, natural

do comportamento humano, alguns pesquisadores têm utilizado outras formas simbólicas para representar suas reivindicações de conhecimento (HASEMAN, 2006, p. 45).

2. O corpo não é um meio por onde a informação simplesmente passa, pois toda informação que chega entra em negociação com as que já estão presentes. O corpo é o resultado desses cruzamentos, e não um lugar onde as informações são apenas abrigadas. É com essa noção de mídia de si mesmo que o corpomídia lida, e não com a ideia de mídia pensada como veículo de transmissão (GREINER; KATZ, 2005, p. 7). 
do município de Fortaleza, morou em Russas, retornou para Fortaleza, atualmente se encontra no estado do Amapá e desenvolve pesquisa de doutorado pelo programa de pós-graduação em Artes da Universidade Federal do Pará, na cidade de Belém.

Esses artistas nômades estão imersos no processo de construção poética, comunicando-se por via virtual, por meio de plataformas digitais que também se mostram como ambientes de criação. Nesse processo, começam a surgir questões levantadas a partir da discussão desse coletivo, que vão alicerçando o processo de criação.

Nessa perspectiva, as discussões trilharam para uma série de perguntas que esses artistas, enquanto investigadores, se depararam. Essas perguntas trazem em si a ideia de "perguntas-passaporte" proposta por Sônia Rangel, apontada anteriormente como uma importante contribuinte no nosso processo. Para a autora, as perguntas-passaporte da pesquisa são capazes de induzir o pesquisador "a transpor a cartografia da obra em profundezas e extensões nunca dantes atingidas" (RANGEL, 2008, p. 3). Exatamente na busca pela profundidade e para dar extensão às inquietações primeiras da pesquisa é que nós, os artistas investigadores nômades, levantamos duas perguntas-passaporte que até o momento nos guiam na investigação.

PERGUNTAS-PASSAPORTE:

1. Que pensamentos governam a minha prática?

2. Qual princípio norteia minha prática?

Essas perguntas-passaporte derivam das leituras sobre processo de criação no trabalho de pesquisa poética de Sonia Rangel. Desse modo, na tentativa de responder a tais questões, os artistas nômades levantaram duas respostas que se tornaram os dois principais elementos da investigação até o momento.

Similar ao trabalho de Sônia Rangel, a primeira pergunta-passaporte é respondida a partir de uma imagem. A autora nos fala que "nesse contexto princípios/propostas, processos e produtos incluem a imagem como um grande operator" (RANGEL, 2006, p. 1). A imagem que surge a partir da indagação do grupo é a casa. Essa imagem traz consigo a potência da relação de deslocamento, ora se dando como signo de imobilidade, ora se desdobrando para campos de compreensão expandidos, chegando à ideia da casa como 
lugar transitório, que se constrói a cada movimento do nômade. Desse modo, a imagem da casa se mostra a representação de uma condição de constante reterritorialização.

Para a segunda pergunta-passaporte, chegamos à reflexão de que o princípio norteador de nossa prática estava presente no outro. A relação de agenciamentos, a relação de um com o outro, a construção em coletivo, no outro e com o outro. A relação nômade, à medida que cada outro é um território desterritorializado em potência que, na relação com o outro, opera em movimentos de reterritorializações.

$\mathrm{Na}$ inter-relação desses dois territórios, o da casa e do outro, ainda sob a influência da obra de Sônia Rangel, o trabalho vai se configurando. Assim, tendo como referência três imagens propostas pela autora, buscamos relacionar as duas imagens operativas de nossa pesquisa. Assim, a casa e o outro se encontram. Nesse encontro, a casa ganha mais duas dimensões territoriais, derivadas das propostas de Sônia Rangel: o quintal e o jardim.

Desse modo, chegamos a uma convergência com a proposta da autora e elaboramos a relação desses espaços imagéticos com o elemento do outro.

Assim, nos questionamos onde e como habitam cada outro nesses espaços imagéticos.

No jardim, portanto, habitam todos, vista a sua relação com o que se mostra para o exterior. Assim, o jardim estaria na frente da casa, mostrando ao território externo o resultado de nossa pesquisa. Dessa forma, o jardim se encarrega dos processos de reterritorialização (desterritorializações territorializantes).

Na casa habita ninguém, pensada esta como a própria representação do trânsito - ambiente de transição entre o jardim e o quintal -, lugar onde não se estaciona, de atuação do nômade. É na casa que os agenciamentos ocorrem.

Já no quintal habito eu, na figura do pesquisador/provocador do processo. É no quintal onde os processos são pensados e de onde eles partem. É também nesse ambiente que a tentativas se encontram, onde o inacabado habita, onde o ainda por vir se configura.

A partir desse levantamento de imagens e relações, iniciamos o processo prático no qual esses elementos operam de maneira direta no processo de criação artística. 
Partindo da proposição de uma pesquisa poética, o objeto de pesquisa se transfigura em um objetivo. Assim, o objeto da pesquisa configura-se em um objetivo, levando em consideração as consequências de uma pesquisa em processos de criação.

Assim, o objetivo desta pesquisa se dá na realização de uma obra artística por meio do compartilhamento de saberes poéticos entre artistas nômades, tendo como ambiente de construção os meios digitais. Um possível ser/ corpo que, ao mesmo tempo que é um, é todos, e habita(m) esse(s) espaço(s) em simultaneidade de presença.

Este trabalho transcorrerá a partir das imagens geradas nas perguntas-passaporte: a casa e o outro. A proposta é trabalhar em uma obra híbrida que relacione teatro, audiovisual, instalação e intervenção. Cada artista nômade realizará sua participação na obra, no lugar onde se encontra, no instante em que está, na cidade e casa onde habita no momento. Explorando os espaços de suas casas, o trabalho se expande pelo espaço cibernético, trazendo com isso duas noções operativas: as noções de cíbrido e de ubiquidade.

Segundo Peter Anders (2001), a noção de cíbrido está diretamente ligada a uma fusão entre atualidade e virtualidade. No trabalho aqui relacionado, especificamente, existe uma relação entre espaço cibernético e espaço físico. Já por ubiquidade se entende a capacidade de estar em diversos lugares simultaneamente, capacidade esta cada vez mais possibilitada pela presença dos dispositivos e ambientes virtuais.

Assim, o trabalho se dá na construção do que por hora estamos chamando de espaço-outro, que seria exatamente este espaço de criação artística cíbrido capaz de comportar os sujeitos em sua qualidade ubíqua.

Dessa forma, o modus operandi do trabalho procede da seguinte forma:

1. Criação do espaço-outro

2. Ocupação do espaço-outro

3. Intervenção no espaço-outro

A criação do espaço-outro ocorre nos ambientes virtuais. Para tanto, podem ser utilizadas plataformas de transmissão de vídeo em tempo real, a chamada tecnologia stream. Transmissões ao vivo no ambiente virtual do Facebook, YouTube ou Instagram são exemplos de possibilidades de criação 
de espaços-outros. Uma vez iniciada uma transmissão, temos a criação deste espaço-outro que, ao mesmo tempo em que transmite imagens de um lugar real, gera um lugar no ambiente virtual, daí um processo cíbrido.

Figura 1 - Telas da transmissão ao vivo na plataforma do Facebook (um possível espaço-outro)
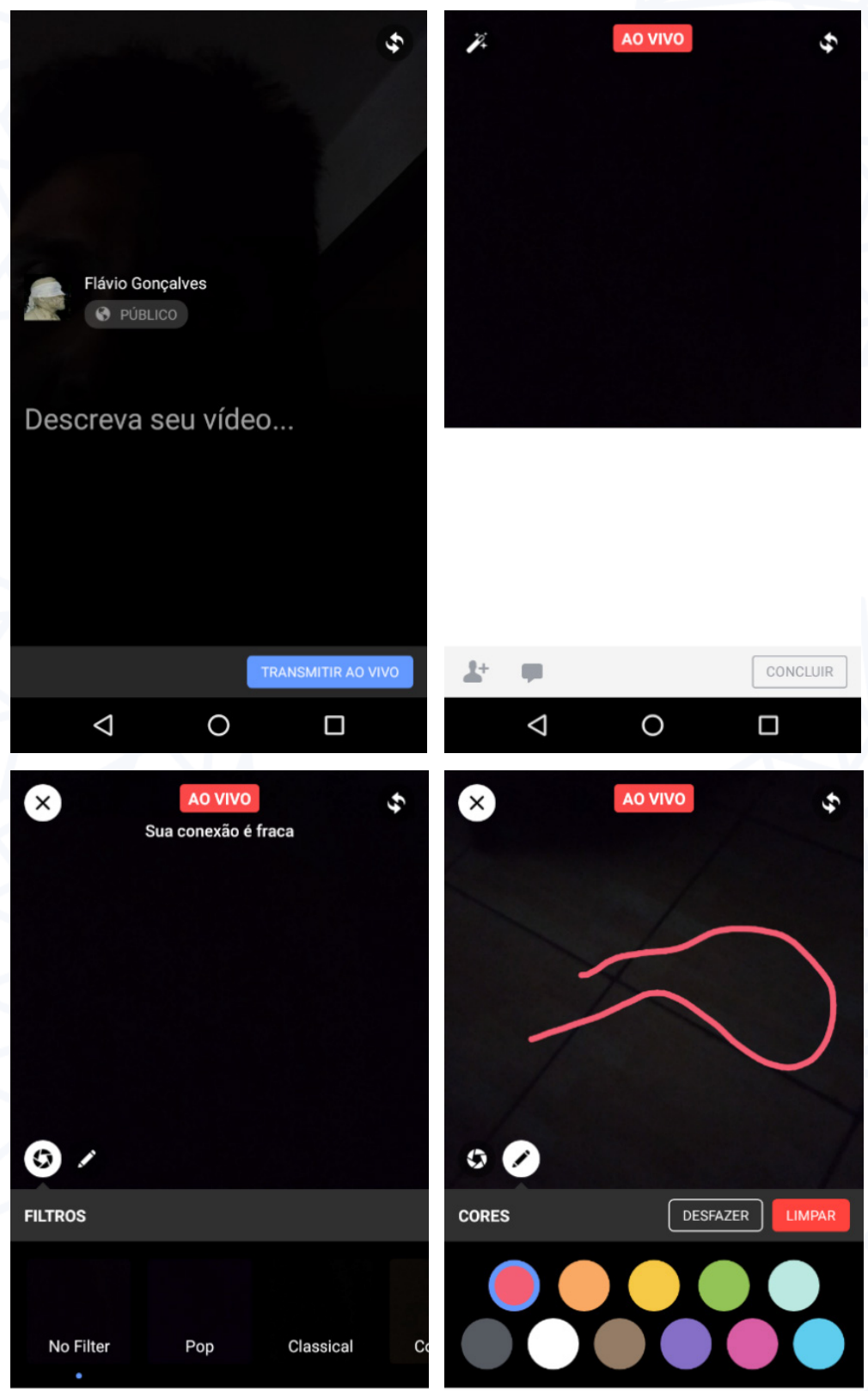

$$
\triangleleft
$$

○

$\square$

\section{$\triangleleft$}

$\mathrm{O}$

$\square$

Fonte: Acervo pessoal.

Uma vez criado esse espaço, é possível dar vez a sua ocupação. Essa ocupação é estabelecida via espectador. Qualquer sujeito, em qualquer lugar 
do mundo, a partir do momento em que inicia a visualização da transmissão começa a ocupar esse espaço-outro.

Desse modo, cria-se uma plateia em rede, em uma situação de ubiquidade, pois, ao mesmo tempo que se encontra em seu lugar de presença real, transporta-se para o espaço-outro por meio de sua presença virtual na transmissão. Cria-se, portanto, uma plateia que, além de real, é virtual.

Por fim, ocorre a última etapa desse processo, em que há a intervenção no espaço-outro. Essa intervenção decorre de mecanismos que modificam o vídeo por meio de filtros, ou mesmo de ferramentas de desenho na tela em tempo real.

A partir dessas três etapas realiza-se a obra artística nômade, considerada, aqui, como um espetáculo de teatro em um ambiente virtual.

\section{Exercício nômade 1 - Corpo-porto}

Trata-se de uma videoperformance feita pelo coletivo TensoAtivo em Macapá. No trabalho, os performers escreviam bilhetes para pessoas situadas em locais distantes e, depois, faziam barquinhos de papel com esses bilhetes. Por fim, os barquinhos eram depositados no rio Amazonas, na maré baixa e, a partir do processo de cheia do rio, eram levados e dissolvidos pela água.

Figura 2 - Registro fotográfico do exercício nômade 1

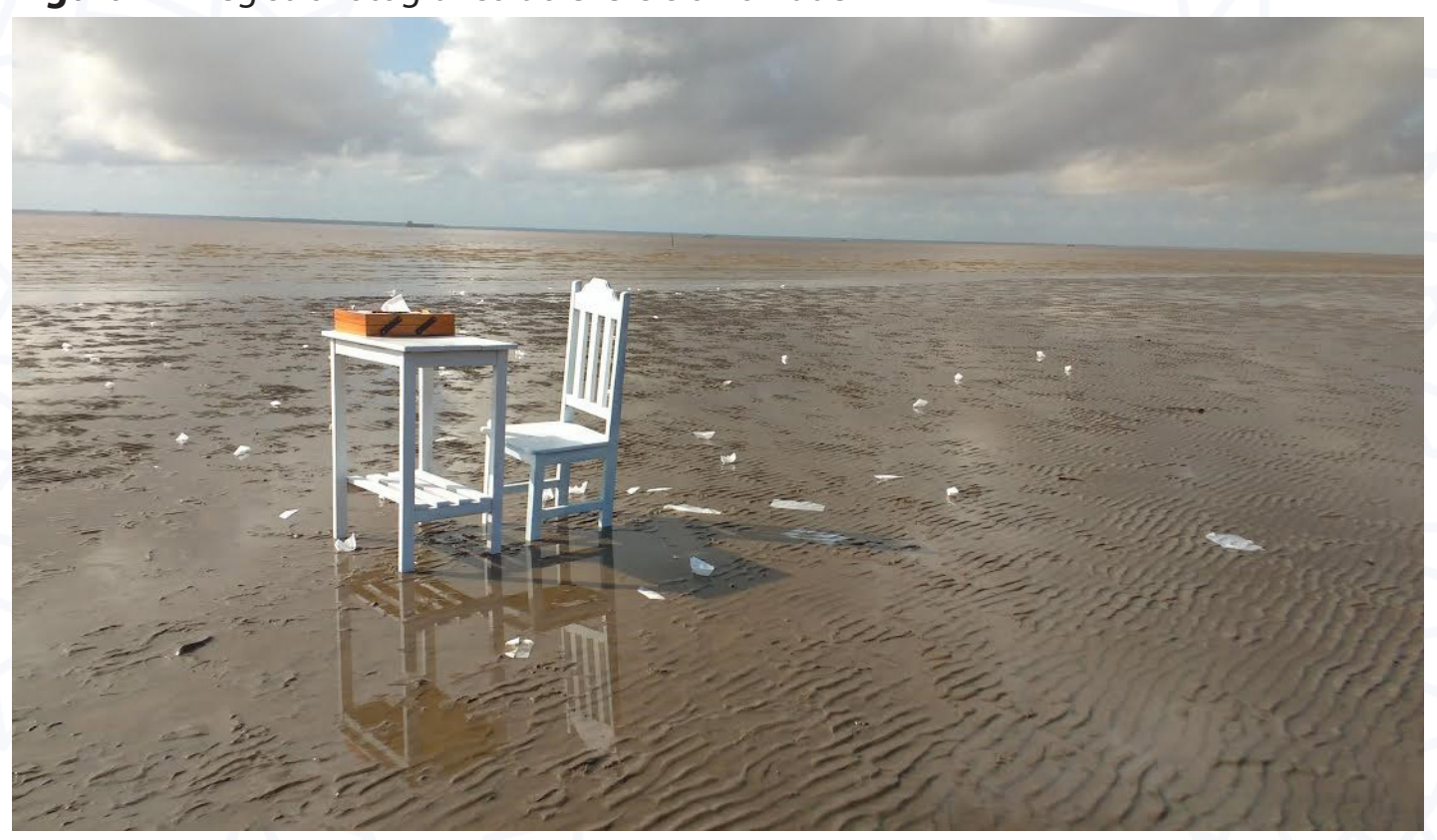

Fonte: Acervo pessoal. 


\section{Exercício nômade 2 - Exercício de nomadologia}

Performance realiza na cidade de Macapá, no monumento Marco Zero (que marca a linha do Equador). Na performance, o artista molhava seus pés em uma lama de argila e caminhava pelo monumento, deixando suas pegadas pelo espaço. Na finalização do trabalho, ele percorria todo o caminho marcado arrastando-se pelo chão e incorporando a si as marcas deixadas no espaço.

Figura 3 - Registro fotográfico do exercício nômade 2

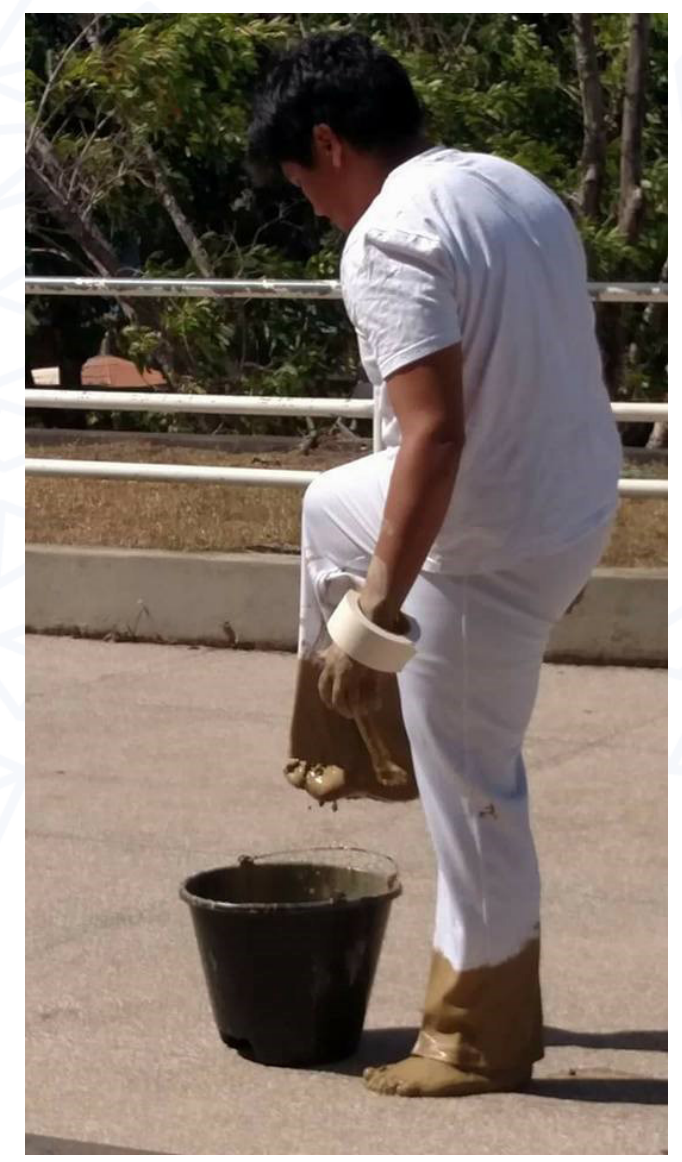

Fonte: Acervo pessoal.

\section{Exercício nômade 3 - Caminhar-registro}

O exercício consistiu em filmar os pés durante uma caminhada. No caso deste experimento, o artista nômade teve o seu percurso filmado, de sua casa até o prédio do Programa de Pós-Graduação em Artes da Universidade Federal do Pará. 


\section{Exercício nômade 4 - Ver(EU)-Descrever(OUTRO)}

Esse exercício propõe descrever um lugar marcante onde o artista nômade tenha ido e, ao mesmo tempo, mostrar as imagens do lugar no qual o artista se encontra no momento.

Como dito anteriormente, esses exercícios se mostram na perspectiva da construção do material para a criação da obra nômade para a qual se volta esta pesquisa.

Assim, esses experimentos se desdobrarão em quadros/células poéticas que constituirão o espetáculo no espaço-outro. Assim, estas e outras experiências que surgirão no decorrer do processo servirão como disparos para estas cenas que se realizarão no ambiente das casas dos artistas nômades e que será transmitido via ambiente virtual.

Por fim, caminho a partir deste ponto para a conclusão deste artigo. Considerando como um registro de passagem que, por hora, tenta dar conta do andamento da pesquisa, este caminhar de um nômade, este escrito aqui apresentado, se mostra como rastros, pegadas que se fixam no caminho percorrido, que ao passo que se mantém como marca, também se permite mover-se em dinâmicas e fluxos próprios do pensamento envolto de uma pesquisa poética.

Assim, encerro esta caminhada pelo território movediço da pesquisa poética aqui proposta, consciente de que ela ocorre por via da claudicação, como diria Jean Lancri, uma vez que a pesquisa em poéticas "segue o passo (ainda uma metáfora) tanto do sábio quanto do poeta, tanto dos donos da razão quanto dos profissionais do sonho" (LANCRI, 2002, p. 23). Estaria eu, portanto, nesta pesquisa, na condição do nômade a caminhar coxeando, agenciando territórios do sensível e da razão.

\section{Referências bibliográficas}

ANDERS, P. Toward an architecture of mind. In: CAIIA-STAR SYMPOSIUM: EXTREME PARAMENTERS. NEW DIMENSIONS OF INTERACTIVITY, 2001, Barcelona.

Proceedings... Barcelona: Universitat Oberta de Catalunya, 2001.

DELEUZE, G.; GUATARRI, F. Mil Platôs. 2. ed. São Paulo: Editora 34, 1997. v. 4.

GONÇALVES, F. Um argumento frágil. Revista Porto Arte, Porto Alegre, v. 16, n. 27, p. 137-145, 2009. 
HASEMAN, B. A manifesto for performative research. Media International Australia incorporating Culture and Policy: Quarterly Journal of Media Research and Resources, Brisbane, QLD, n. 118, p. 98-106, 2006.

KATZ, H.; GREINER, C. Por uma teoria corpomídia. In: GREINER, C. O corpo: pistas para estudos indisciplinares. São Paulo: Annablume, 2005. p. 125-134.

LANCRI, J. Modestas proposições sobre as condições de uma pesquisa em Artes Plásticas na universidade. In: BLANCA B. TESSLER, E. O meio como ponto zero: metodologia da pesquisa em artes plásticas. Porto Alegre: UFRGS, 2002.

LÉVY, P. O que é virtual? São Paulo: Editora 34, 2007.

NOVAES, A. Muito além do espetáculo. São Paulo: Senac, 2005.

RANGEL, S. Processos de criação: atividade de fronteira. In: CONGRESSO BRASILEIRO DE PESQUISA E PÓS-GRADUAÇÃO EM ARTES CÊNICAS ABRACE, 4., 2006, Rio de Janeiro. Anais... Rio de Janeiro: Universidade Federal do Estado do Rio de Janeiro, 2006. 1-6.

Perguntas-passaporte: mão dupla nas fronteiras da criação. In: CONGRESSO BRASILEIRO DE PESQUISA E PÓS-GRADUAÇÃO EM ARTES CÊNICAS ABRACE, 5., 2008, Belo Horizonte. Anais... Belo Horizonte: Universidade Federal de Minas Gerais, 2008. p. 1-4.

SALLES, C. A. Redes da criação: construção da obra de arte. 2. ed. Vinhedo: Horizonte, 2008.

Recebido em 01/10/2017

Aprovado em 25/11/2017

Publicado em 03/05/2018 